\title{
Abrasiveness evaluation of rock-cone bit based on fractured cuttings
}

\author{
Changhao Wang ${ }^{1}$ D $\cdot$ Shibin $\mathrm{Li}^{1}$
}

Received: 14 January 2018 / Accepted: 8 April 2019 / Published online: 19 April 2019

(c) The Author(s) 2019

\begin{abstract}
This paper looks at the influence of the sorting coefficient, average particle size and quartz content on the abrasion rate of the cone bit. This paper uses rock drillability experiments, particle sizing tests and XRD mineral component analyses as methodology. The results show that the larger the average particle size and sorting coefficient, the smaller the real contact area between the bit and the rock surface, the smaller the friction force. Meanwhile, the volume of the fractured cuttings increased. The results also show that the less the quartz content, the less hard points in the rock. All these factors lead to the reduction in drill bit damage. Because of the strong correlation among the factors of abrasiveness, this paper develops a model of the drill bit abrasion using the partial least square method. The main factors of the model are the grain size distribution and the quartz content of the rock. This model can also be used in the selection of drill bit type and the classification of rock abrasion.
\end{abstract}

Keywords Drill damage $\cdot$ Abrasion $\cdot$ Average particle size $\cdot$ Sorting coefficient $\cdot$ Partial least squares regression

In the drilling process, the cone bit will wear and get blunt during the process of breaking the rocks. The wearing of the drill bit reduces the rock cutting rate, which adds some additional time to the drilling operation, and leads to the considerable reduction in drilling efficiency. Therefore, researchers are concerned about rock abrasiveness to the drill.

There have been many studies about drill damage when drilling for oil into rock (Yaralı et al. 2008; Okubo et al. 2011; Oparin and Tanaino 2009; Zhang et al. 2012). Most of these studies do not study at the site of drilling, but instead use rock samples. This method is inadequate to study drill abrasion. On the one hand, the bit wearing process is very complicated, which is restricted by the working conditions in the field; on the other hand, due to the complex underground lithology and the variability of rock core, it is impossible to take accurate samples which represent coring from the whole formation. The lack of accurate studies leads to continued problems in the selection and usage of the drill bits (Wang and Luo 1988). In addition, laboratory tests can only be performed after the actual drilling, cost a lot and take a long time.

Changhao Wang

229166411@qq.com

1 Key Laboratory of Enhanced Oil Recovery, Ministry of Education, Northeast Petroleum University, Daqing 163318, Heilongjiang Province, China
To solve the above problems, this paper looks at the influence of the sorting coefficient, average particle size and quartz content on the abrasion rate of the cone bit. This paper uses rock drillability experiments, particle sizing tests and XRD mineral component analyses as methodology. Instead of bringing samples back to the laboratory for testing, the cuttings are tested on site. So making the cuttings returned from bottom hole as the research object, the testing process can be done while sampling. It is conducive to solving the disadvantages existing in the traditional laboratory test methods, such as the lag, higher cost and so on.

\section{The experiment part}

There are 10 cores with different lithologic character selected in the experiment, and the coring information is shown in Table 1.

\section{Drillability experiment of cone bit}

Based on the SY/T 5426-2000 standard, the drillability experiment can be carried out. The experimental device is a fully automatic rock drilling test instrument produced by ShanDong ShiYi Science and Technology Co. Ltd. of U.P.C, as shown in Fig. 1. Test conditions are as follows: drilling pressure $W=889.7 \mathrm{~N}$, rotation speed $N=55 \mathrm{r} / \mathrm{min}$, drill 
Table 1 Coring information

\begin{tabular}{lllcll}
\hline Number & Well name & Lithologic character & Number & Well name & Lithologic character \\
\hline 1 & Xushen22 & Glutenite & 6 & Shuangshen10 & Sand shale \\
2 & Yingshen1 & Tuff & 7 & Xushen9 & Rhyolite \\
3 & Yingshen1 & Gray black mudstone & 8 & Shangshen3 & Silt \\
4 & Chaoshen5 & Acidic eruption rock & 9 & Shangshen3 & Glutenite \\
5 & Weishen5 & Glutenite with mudstone & 10 & Changshen101 & Medium sand \\
\hline
\end{tabular}

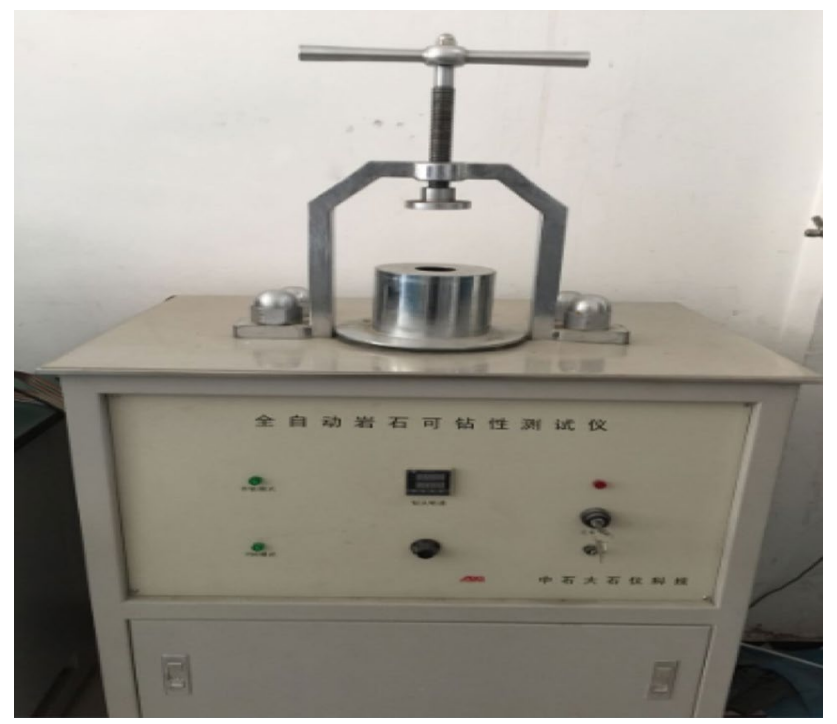

Fig. 1 Fully automatic rock drilling test instrument

diameter $D=31.75 \mathrm{~mm}$ (it is made up of eight hard alloy material slices with the thickness of $2.5 \mathrm{~mm}$ and the hardness of $\mathrm{HRC} \cong 58$ ). The sample was placed on a clamping system and drilled with a micro-piston bit. When the drilling time is $300 \mathrm{~s}$, the volume of rock breaking and the weight of the bit before and after the experiment should be recorded (Li et al. 2003; Oparin and Tanaino 2009). The experimental results are shown in Fig. 2.
The weight of the lost amount of the cone bit through wear and tear when breaking one unit volume of rock as a measure of relative wear rate is represented by $\omega$ (unit: $\mathrm{mg}$ / $\mathrm{cm}^{3}$ ):

$\omega=\frac{\Delta W}{\Delta V}=\frac{\text { Cone bit abrasion weightlessness }}{\text { Rock crushing volume }}$

The index indicates the relative strength of the rock to the cutting tool. This can help with making predictions about rock fragmentation and bit wear. It reliably expresses drill strength with similar results over multiple tests, and it is easy to perform during the drilling process (Xiang 2014).

\section{Cuttings size screening}

Particle size analysis refers to the determination of different sizes of particles in the rock content. It is not only widely used in measuring sedimentary rock formations and depositional environments, reservoir rock classifications and evaluations, but also used in measuring the abrasiveness of rock. Through a set of sieves with different sized apertures, the cuttings obtained from drillability experiments are screened. The standard sieves are arranged in sequence, and sieve diameter is classified from 2 to $0.05 \mathrm{~mm}$, while particles less than $0.05 \mathrm{~mm}$ are treated as coarse silt $(0.05-0.03 \mathrm{~mm})$. The sample was put into the top of the upper sifter, the top was covered, and it was put on the vibration sieve machine screening about $5 \mathrm{~min}$. Then, the lower sieve was removed,
Fig. 2 Part of the experimental results of the sample

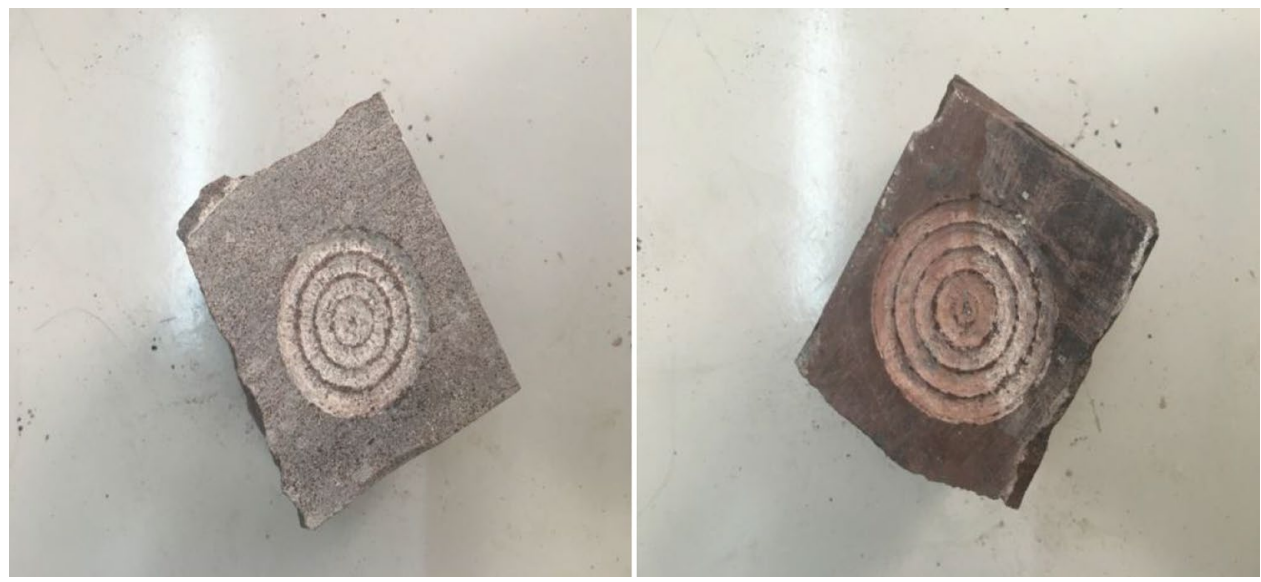


the screening on glossy paper was checked by hand, and the screening quality of each layer was recorded. The screened cuttings are shown in Fig. 3.

\section{XRD mineral component analysis}

Through carrying out X-ray diffraction of the rock, analyzing its diffraction pattern, the research methods of various kinds of information are obtained, such as the composition of the rock, the structure of the internal atoms or molecules. The instruments used in the experiment are TD-3500 X-ray diffraction.

The cuttings obtained from drillability experiment can be ground so that its fineness is about 45 microns. The test conditions are: using progressive scanning method, X-ray $(\mathrm{Cu})$ : voltage of $40 \mathrm{kV}$, current of $30 \mathrm{Ma}$; angle: separation degree of $1.0 \mathrm{deg}$, scanning degree of $1.0 \mathrm{deg}$, acceptability of $0.3 \mathrm{~mm}$; scan: drive shaft of 1Theta-2Theta linkage, scanning range of 10.0-30.0, scanning method for continuous scanning, scanning speed of $2.0 \mathrm{deg} / \mathrm{min}$, sample tilt of $0.05 \mathrm{deg}$; adjust time of $1.50 \mathrm{~s}$. The experimental data are analyzed by the whole-rock XRD analysis software, and the quartz content of the 10 sample groups is obtained. Some experimental results are shown in Fig. 4.

\section{Results and discussion}

\section{The influence of particle size}

When the rock is broken, the mineral particles at the junction are first broken. In most cases, the particles themselves are not broken, leading to the drill bit be worn by the rock mineral and the broken particles (Suana and Peters 1982; Rostami et al. 2013). In this paper, through the drillability test instrument the abrasiveness of the rock can be measured. Drilling from down to up, the effect of three-body wear among the rock cuttings, rock and drill bit is eliminated (Wen and Huang 2012; Chen 2008), and only the wear between the broken particles and the cone bit is considered.

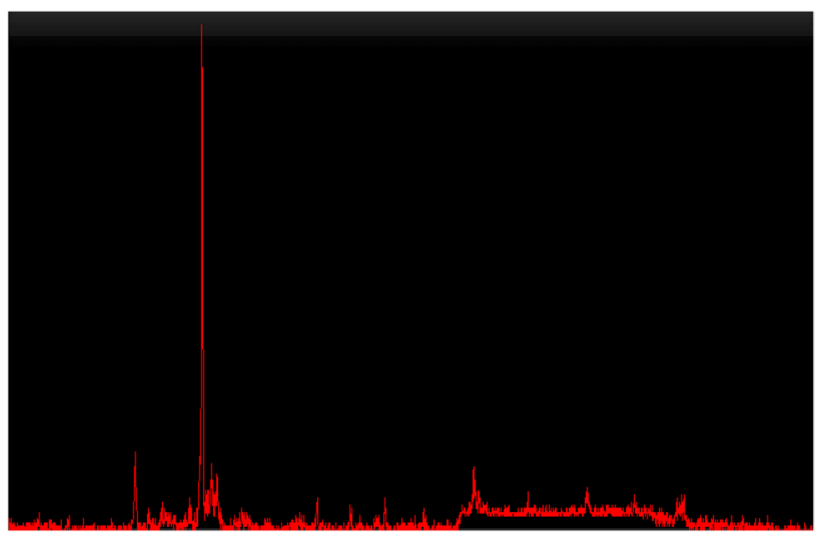

Fig. 4 XRD spectrum of core 1

1. The cuttings' average particle size.

Corresponding to the cumulative percentage, respectively, of $16 \%, 50 \%, 84 \%$ in the cumulative curve, the average of the three particles size is the average size of the particles (Tan et al. 1995). If the logarithmic particle size $\phi=-\log _{2} D$ is used, where $D$ is particle size, then:

$M_{\mathrm{z}}=\left(\phi_{16}+\phi_{50}+\phi_{84}\right) / 3$

$M_{\mathrm{z}}$ has a high representative summarized more than $2 / 3$ of the total size of the sample. When its value is larger, it represents smaller particles and vice versa.

Screening the particles obtained in drillability experiment, there are 10 sample groups by size distribution ranging from 0.5 to $0.03 \mathrm{~mm}$. According to the cumulative curve in Fig. 5, incorporating the size values corresponding to the cumulative mass percentage into formula (2), the average particle size of each rock can be acquired. Then, through formula (1), the abrasiveness of the rock on the drill is calculated, shown in Fig. 6.

Figure 6 shows that with the increase in average particle size of the cuttings broken, the wear rate of cone bit tends to decrease. When the same volume of cuttings is broken, the smaller the particle size, the more the number of particles. This means that more particles are distributed on the rock surface per unit area. When the rock is broken by cone bit, their real contact area is large and it is proportional to
Fig. 3 A picture of screening cuttings

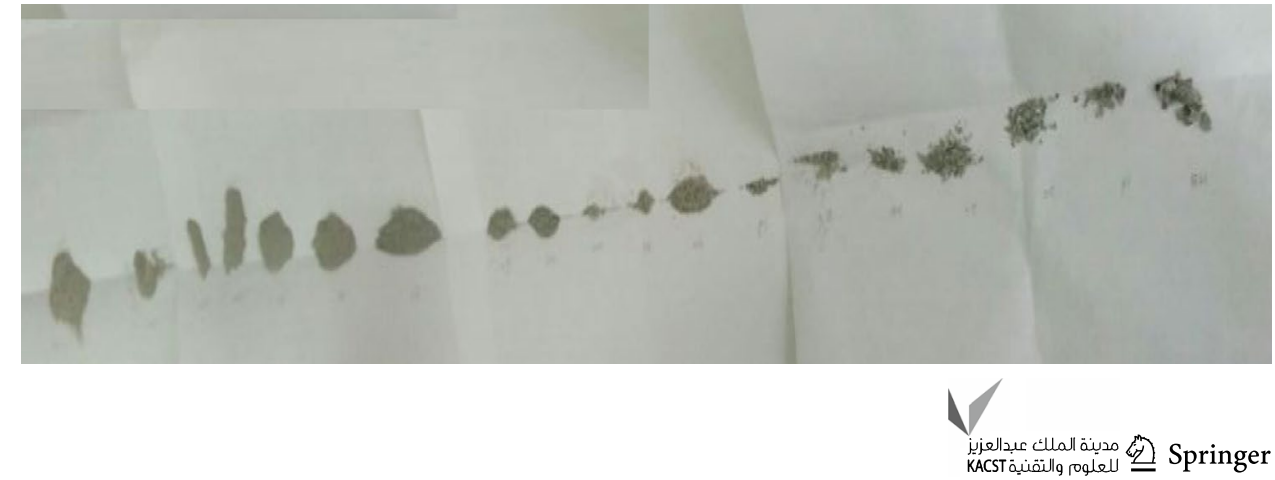




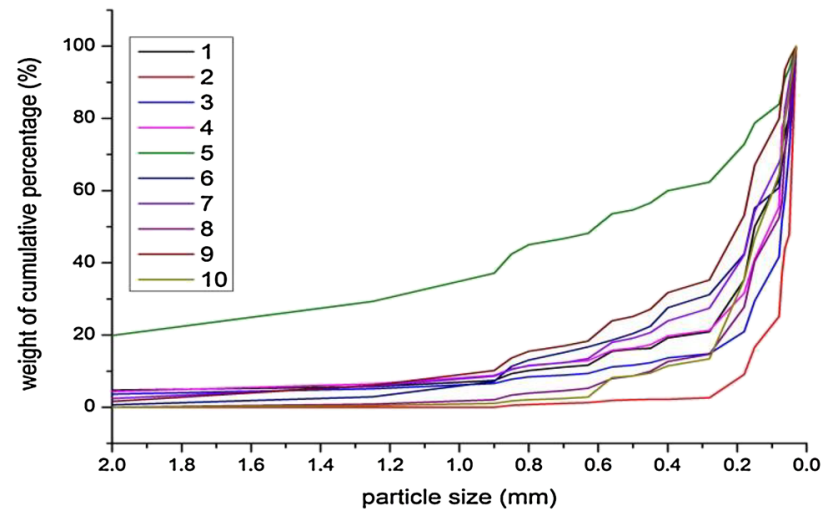

Fig. 5 The accumulation curve of cuttings weight

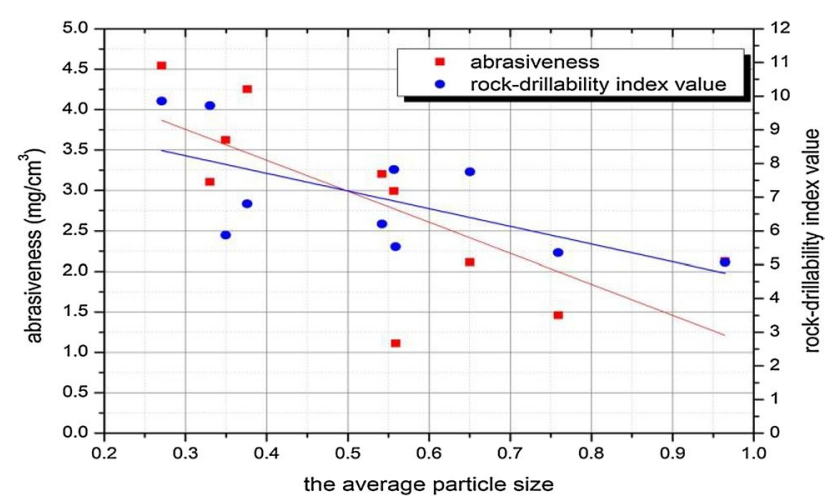

Fig. 6 The impact of the average particle size on rock drillability and abrasiveness

the value of the friction force (Wang 2003); therefore, the meshing force between the rock and bit micro-convex body will become larger. The friction force of the contact surface has an important effect on fatigue wear, and even a small amount of sliding will increase the bit wear capacity significantly (Ka et al. 2015; Fu et al. 2010). On the contrary, when the average particle size becomes larger, the bit wear capacity caused by the hard particle on the rock surface will decrease with the decrease in the friction force. On the other hand, the larger particle can decrease the bit power consumption in unit volume of broken rocks; that is to say, the rock drillability grade becomes smaller and the breaking volume increases in unit time. According to formula 1, the larger the particle size of rock broken, the weaker the rock abrasiveness for bit.

2. The cuttings sorting coefficient.

Sorting coefficient is the parameter used to characterize the uniformity of the broken particle. According to P. D. Trask's claim, it is the ratio of the particle size corresponding to the cumulative percentage of $25 \%$ and $75 \%$ in cumulative curve, namely:

$S_{D}=D_{25} / D_{75}$

$S_{D}$ is generally greater than 1 . And the closer it approaches 1 , the better the sorting characteristics. Putting the value of the cumulative mass percentage into formula (3), the sorting coefficient of the rock broken particles can be obtained. Its influence on the drillability and abrasiveness of the cone bit is shown in Fig. 7.

According to Fig. 7, the more dispersive the broken rock particle distributed, the lower the abrasiveness of the rock. When the sorting coefficient of the rock broken particles is larger, the nonuniform particles are dispersed in the rock surface making its surface rougher, and the actual contact area between bit and the rock is smaller (Yue et al. 2001; Han et al. 2009). Therefore, the physical and mechanical properties of the rock in contact area should be equivalent to the analysis in the case of the large average particle size; that is, the friction force between the bit and the rock micro-convex body is small. At the same time, the huge contact pressure produces between the contact points, which led to the flaking of the rock cuttings without wearing the bit surface (Atkinson et al. 1986). The greater the sorting coefficient, the less the bit wear. What is more, due to the decrease in the value of the rock drillability grade, it is more likely for the particles to fall off, and the abrasiveness for rock to bit gets weak.

\section{The influence of rock quartz content}

Figure 8 shows the XRD spectrum of the cuttings after core 1 drillability experiment by processing Fig. 3. All phases have their own diffraction characteristic curves corresponding to the various states which they are in. When the X-ray passes through the cuttings, a specific diffraction pattern is produced, corresponding to a series of interplanar spacings $d$ and satisfying the Bragg law $2 d \sin \theta=n \lambda$, where $\theta$ is the

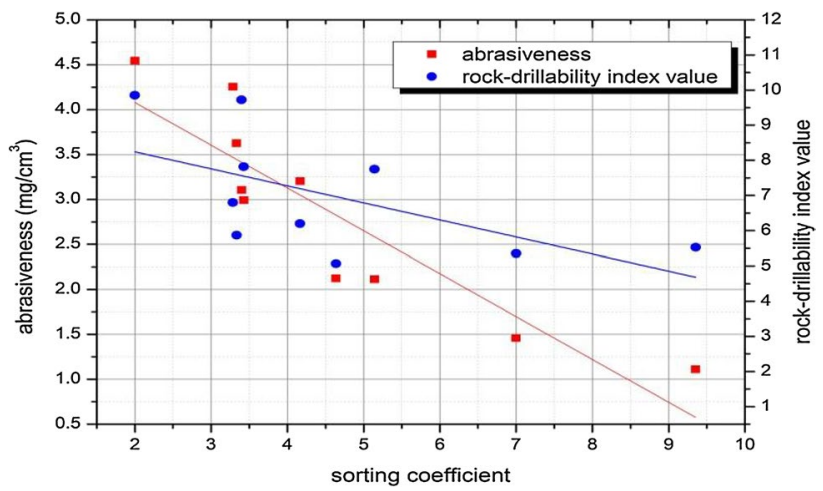

Fig. 7 The influence law of sorting coefficient on rock drillability and abrasiveness 


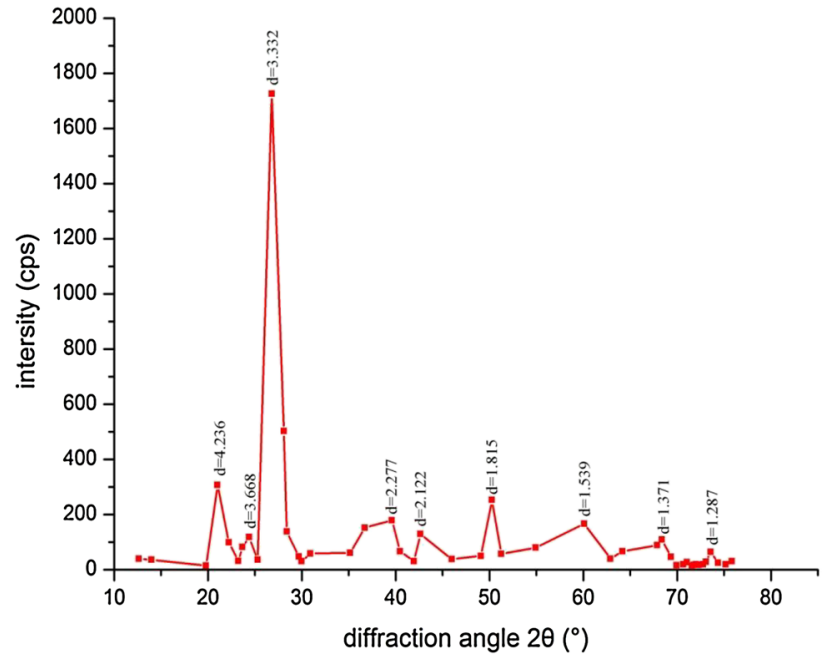

Fig. 8 Peak on XRD spectrum of cuttings

angle between incident $\mathrm{X}$-ray and lattice plane, $\lambda$ is the wavelength of the X-ray, and $n$ is the diffraction order. Therefore, applying the whole core analysis software to search for the peaks in the spectrum of cuttings and calculate the $d$ value, we can get the main mineral components of the test core sample. Since the hardness of the rock particles plays a main role in wearing bit (Huo et al. 2005; Yang et al. 2014), this paper makes the quartz particles as the study object and analyzes the wear of different contents of cone bit. There are ten groups' data of the quartz content and cone bit abrasion shown in Table 2.

Figure 9 shows the relationship between the core quartz content and the rock drillability and abrasiveness, respectively. When the quartz content increases, there is no obvious change in the grade value of the drillability, while the abrasiveness increases. It is easy to understand that with the increase in the quartz content in the rock, the number of the hard spots increases, and due to the friction and breaking effect of the hard points, the wear capacity of cone bit increases in unit time (Zhao et al. 2011; Ge and Zhu 2005). While the rock drillability is constant, the rock breaking

Table 2 Quartz content and abrasiveness

\begin{tabular}{llllll}
\hline $\begin{array}{l}\text { Number } \\
\text { content, } \\
\%\end{array}$ & $\begin{array}{l}\text { Abrasive- } \\
\text { ness, mg/ } \\
\mathrm{cm}^{3}\end{array}$ & Number & $\begin{array}{l}\text { Quartz } \\
\text { content, } \\
\%\end{array}$ & $\begin{array}{l}\text { Abrasive- } \\
\text { ness, mg/ } \\
\mathrm{cm}^{3}\end{array}$ \\
\hline 1 & 54.7 & 3.202 & 6 & 13.2 & 1.460 \\
2 & 56.7 & 4.545 & 7 & 12 & 2.114 \\
3 & 14.3 & 3.104 & 8 & 45.4 & 3.625 \\
4 & 32.9 & 2.992 & 9 & 22.8 & 2.124 \\
5 & 7 & 1.112 & 10 & 66.3 & 4.253 \\
\hline
\end{tabular}

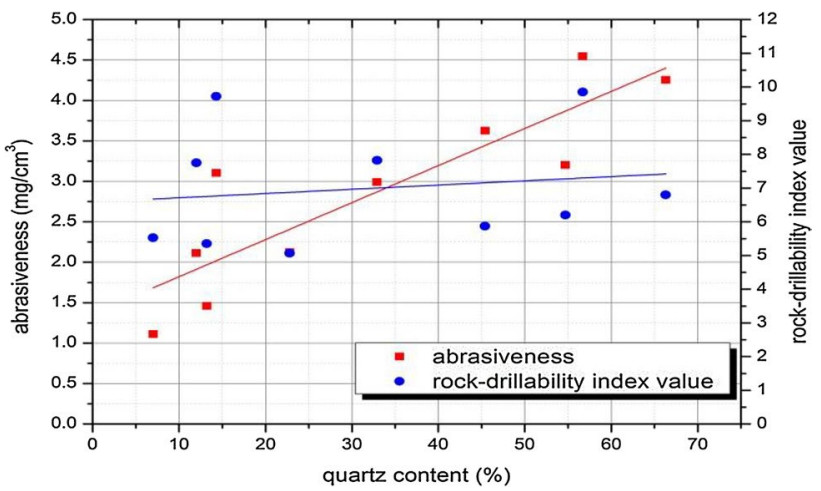

Fig. 9 The influence of quartz content on rock drillability and abrasiveness

volume in unit time stays same, which causes the cone bit abrasiveness to get strong.

\section{The comprehensive evaluation on rock-cone bit abrasion}

According to the above analysis result, the broken rock particle size, sorting coefficient and quartz content have a certain impact on the wear efficiency of the cone bit, but a single factor cannot fully reflect the rock abrasiveness. By the correlation coefficient of $r$ between the variables in Table 3, there also exists strong correlation between the various factors that affect the abrasiveness. Therefore, using the partial least squares regression modeling is more effective than the general regression and ordinary least squares regression $(\mathrm{Lu}$ 2014). Through minimizing the square sum of the error, the best function matching between the factors and abrasiveness parameters can be found to be more accurate.

\section{The establishment of partial least squares regression equation}

The equation is a data set of three independent variables $X=\left\{x_{1}, x_{2}, x_{3}\right\}$, one dependent variable $Y=(y)$ and ten observations. Let $t_{1}$ and $u_{1}$ be the linear combination of $\left\{x_{1}, x_{2}, x_{3}\right\}$ and $y$, and let $t_{1}$ and $u_{1}$ carry as much variation information as possible in the respective data and maximize the correlation between $t_{1}$ and $u_{1}$. When the first components $t_{1}$ and $u_{1}$ are extracted, the regression of the rock parameter $X$ to $t_{1}$ and the abrasiveness index $Y$ to $t_{1}$ is, respectively, performed. As soon as the required accuracy is reached, the algorithm terminates. Otherwise, the main component will be extracted from the residual information left after the data sets of $X$ and $Y$ are interpreted by $t_{1}$. If the final $X$ extracted $\mathrm{m}$ principal components $t_{1}, t_{2} \ldots t_{m}$, the evaluation equation 
Table 3 The correlation coefficient between the variables

\begin{tabular}{lllcr}
\hline$r$ & Quartz content & Average particle size & Sorting coefficient & \multicolumn{1}{c}{ Abrasiveness } \\
\hline Quartz content & 1 & -0.513723921 & -0.690329992 & 0.874780456 \\
Average particle size & 1 & 0.496051373 & -0.727011045 \\
Sorting coefficient & & 1 & -0.900698691 \\
Abrasiveness & & & 1 \\
\hline
\end{tabular}

$0.5 \leq|r|<0.8$ : significant linear correlation; $0.8 \leq|r|<1.0$ : highly linear correlation
Fig. 10 The process of partial least squares regression

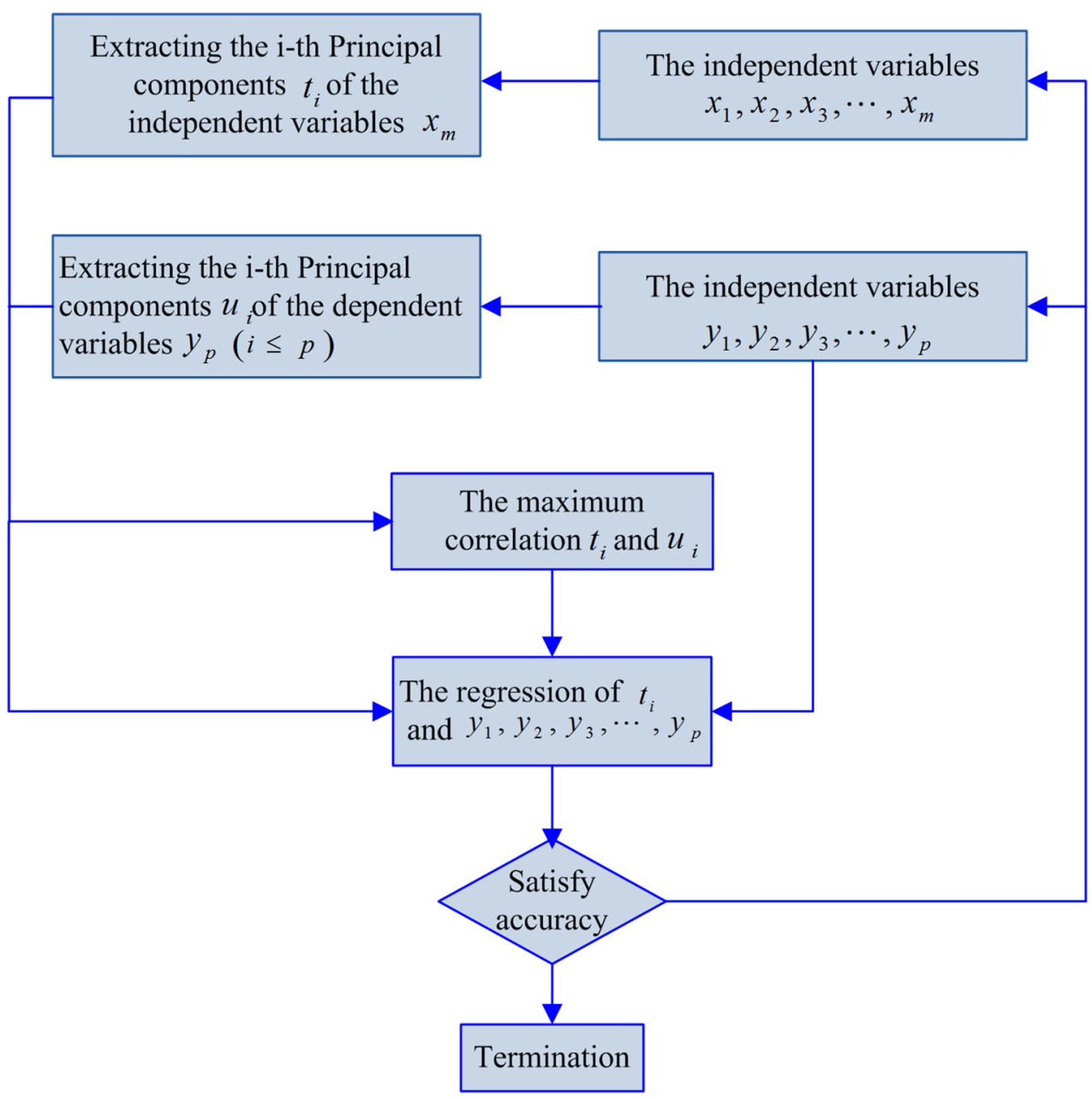

of the rock-cone bit abrasiveness can be established by the regression of $Y$ to $t_{1}, t_{2} \ldots t_{m}$. The implementation process of the partial least squares regression method is shown in Fig. 10.

\section{The evaluation on rock-cone bit abrasiveness}

The principal to determine the main component number of the partial least squares regression is to make least prediction error, and on this basis, two principal components are determined to be extracted. According to the results of data processing, the roles of the quartz content, average particle size and sorting coefficient in explaining the rock-bit abrasiveness are obtained, respectively, which is represented by the variable importance in projection (VIP) (Xu 2006). VIP $j$ reflects the importance of the $j$-th independent variable in interpreting the dependent variable, and the formula is as follows:

$\operatorname{VIP} j=\sqrt{\frac{p}{\operatorname{Rd}\left(Y ; t_{1}, \ldots t_{m}\right)} \sum_{h=1}^{m} \operatorname{Rd}\left(Y ; t_{h}\right) w_{h j}^{2}}$

where $p$ is the number of independent variables; $w_{h j}$ is the $j$-th component of $w_{h}$, and it is used to measure the boundary contribution of $X$ to the structural components $t_{h} ; \operatorname{Rd}\left(Y ; t_{h}\right)$ 


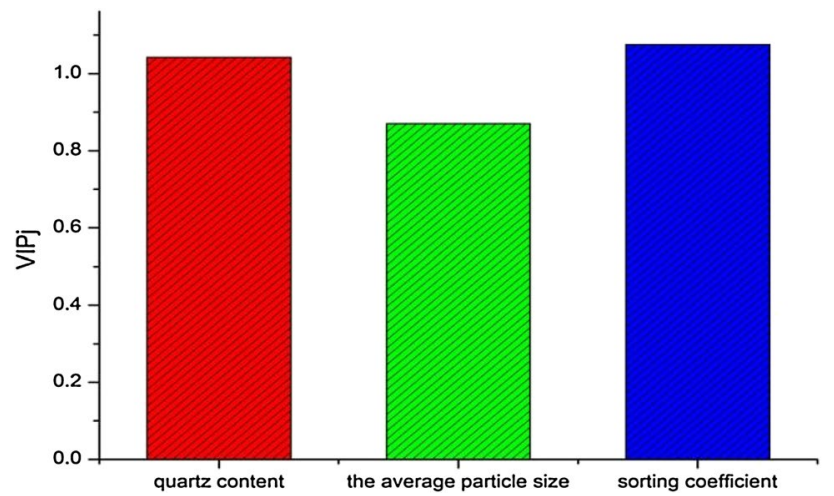

Fig. 11 The variables important in projection

and $\operatorname{Rd}\left(Y ; t_{1} \ldots t_{m}\right)$ are the explanatory ability of $t_{h}$ for $Y$ and the cumulative interpretation ability of $t_{1}, t_{2} \ldots t_{m}$ for $Y$, respectively.

Based on the VIP $j$ value in Fig. 11, these three factors all are important to affect the rock abrasiveness, and the order is as follows: sorting coefficient $>$ quartz content $>$ average particle size.

Calculating the data by using the partial least squares regression method, the regression coefficients of various parameters are obtained as shown in Table 4.

Therefore, the prediction model of rock-bit abrasion is established as follows:

$\omega=4.173+0.02 Q-1.490 M_{\mathrm{z}}-0.259 S_{D}$

where $\omega$ is the abrasion of rock-cone bit; $Q$ is the rock quartz content percentage, $\% ; M_{\mathrm{z}}$ is the average particle size of broken cuttings; $S_{D}$ is the sorting coefficient of broken cuttings.

According to Fig. 12, the prediction formula fitted by the partial least squares method has higher precision and stability than the ordinary least squares regression, with a cumulative variance of the dependent variable that reaches 0.986 . The predicted values can better reflect the magnitude of the actual measured values.

The model comprehensively reflects the rock parameters itself affecting the wear rate of the drill bits in the process of breaking by cone bit, which is universal and versatile. The wear condition of the underground rock to cone bit can be predicted by studying the particle size

Table 4 Regression coefficient

\begin{tabular}{lc}
\hline Independent variable $X$ & $\begin{array}{l}\text { Dependent variable } Y \\
\text { (abrasive property) }\end{array}$ \\
\hline Constant & 4.173 \\
Quartz content & 0.020 \\
The average particle size & -1.490 \\
Sorting coefficient & -0.259 \\
\hline
\end{tabular}

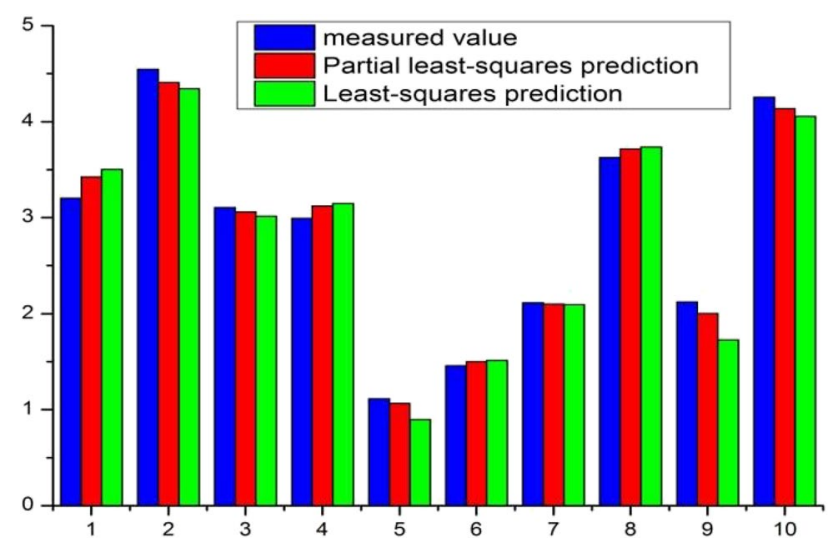

Fig. 12 Partial least squares regression fitting prediction

distribution and quartz content of the upper cuttings during the drilling process ( $\mathrm{Li}$ et al. 2006). It provides the basis for bit selection, as well as the establishment of the classification standard for drill damage.

\section{Applications}

In order to verify the accuracy of the above-mentioned prediction model, Xushen 22 well in the north of Songliao Basin was used as an example to evaluate the abrasiveness. The igneous rock in the strata is widely distributed, including a large segment of intermediate-acid volcanic eruptive rock, rhyolite, glutenite, tuff, basalt, breccia and andesite, and so on. These igneous rocks have many characteristics such as high hardness, strong abrasive and high drillability. The upward debris of Xushen22 well is analyzed and calculated by substituting formula (4). The abrasiveness $\omega$ in $3200-5000 \mathrm{~m}$ is between 4.138 and 4.765 , and the interval belongs to the extremely high-abrasiveness strata. According to the actual drilling data of Xushen22 well, the bit weight during drilling is $200 \mathrm{KN}$ and the speed is $78 \mathrm{r} / \mathrm{min}$. The average footage of the cone bit was $81.53 \mathrm{~m}$, and the ROP was only $2.11 \mathrm{~m} / \mathrm{h}$. After drilling, it was found that both the inner and outer rows of teeth were severely worn. The IADC wear rating was 6-7-WT-A-X-5/16-FC-PR and the cone bit wear rating factor was 5.3 , which proves the accuracy and practicability of the above calculation model for rock abrasiveness. According to the calculation results of the abrasiveness, it is possible to increase the drilling efficiency by replacing the drill bit earlier in the complex strata with high abrasiveness. 


\section{Conclusion}

a. In the drilling process, the deterioration rate of the drill bit is influenced by the particle size of the rock, sorting coefficient and the amount of quartz content. With the decrease in the average particle size and sorting coefficient and the increase in quartz content, the deterioration rate will increase.

b. There exists serious multicollinearity among the various factors. By applying the partial least squares regression, the factors can be ranked by degree of impact (from high to low): sorting coefficient $>$ quartz content $>$ average particle size.

c. We relied on the partial least squares regression, to create our model of drill damage. This paper shows how different features of the rock influence the rate of damage to the drill. This paper has two functions: One is to serve as a reference on which drill type to choose at the site, and the other is to serve as a reference for categorizing rock.

Acknowledgements This study was supported by the Natural Science Foundation of China (No. 51874098).

Open Access This article is distributed under the terms of the Creative Commons Attribution 4.0 International License (http://creativeco mmons.org/licenses/by/4.0/), which permits unrestricted use, distribution, and reproduction in any medium, provided you give appropriate credit to the original author(s) and the source, provide a link to the Creative Commons license, and indicate if changes were made.

\section{References}

Atkinson T, Cassapi VB, Singh RN (1986) Assessment of abrasive wear resistance potential in rock excavation machinery. Int J Min Geol Eng 4(2):151-163

Chen Y (2008) Experimental study of rock-breaking with an offset single cone bit. Pet Sci 5(2):179-182

Fu R, Gao F, Song B et al (2010) Tribological behavior of coppergraphite friction materials. Tribology 30(5):479-484

Ge S, Zhu H (2005) Fractal in tribology. China Machine Press, Beijing, pp 272-303

Han X, Gao F, Song B et al (2009) Effect of friction speed on friction and wear performance of $\mathrm{Cu}$-matrix friction materials. Tribology 29(1):89-96

Huo Y, Yan Y, Liu X et al (2005) Preparation and tribological properties of monodispersed nano- $\mathrm{SiO}_{2}$ particles as additive in lubricating oil. Tribology 25(1):34-38
Ka T, Ruhong S, Enzhu H et al (2015) Tribological behavior of soot particles under reciprocal dry sliding condition. Tribology 32(2):198-205

Li S, Tie Y, Hui H et al (2003) Drillability test study under modeling conditions of bottom hole stress. Nat Gas Ind 23(2):64-66

Li S, Yan T, Li W (2006) Fractal representation of rock drillability. Acta Pet Sin 27(1):124-127

Lu H (2014) Partial least-squares regression models and algorithms research. North China electric Power University, Beijing

Okubo S, Fukui K, Nishimatsu Y (2011) Estimating abrasivity of rock by laboratory and in situ tests. Rock Mech Rock Eng 44(2):231-244

Oparin VN, Tanaino AS (2009) Assessment of abrasivity by physicomechanical properties of rocks. J Min Sci 45(3):240-249

Rostami J, Ghasemi A, Gharahbagh EA et al (2013) Study of dominant factors affecting Cerchar abrasivity index. Rock Mech Rock Eng 47(5):1905-1919

Suana M, Peters $\mathrm{Tj}$ (1982) The Cerchar abrasivity index and its relation to rock mineralogy and petrography. Rock Mech 15(1):1-8

Tan Z, Zheng H, Zhang C et al (1995) Study of the lithology and texture of terrigenous clastic rock with medium grain size and average grain diameter. Well Logging Technol 19(2):130-134

Wang Y (2003) The study of the impact abrasive wear mechanism. Kunming University of Science and Technology, Kunming

Wang Y, Luo H (1988) The ways to improve the drilling effectiveness of the rock bits from tribological view point. Tribology 23(1):504-508

Wen S, Huang P (2012) Principles of tribology. Tsinghua University Press, Beijing, pp 221-335

Xiang Q (2014) The wear mechanism of impregnated diamond bit in igneous rock formation. Northeast Petroleum University, Daqing

Xu F (2006) The study of some problems in partial least-squares regression. Shandong University of Science and Technology, Qingdao

Yang J, Wei X, Hong X et al (2014) Dry friction coefficient of high content $\mathrm{SiC}$ particle reinforced aluminum matrix composite against commercial friction material. Tribology 34(4):446-451

Yaralı O, Yaşar E, Bacak G et al (2008) A study of rock abrasivity and tool wear in coal measures rocks. Int J Coal Geol 74:53-66

Yue C, Jian X, Yong Z et al (2001) The tribological behavior of aluminum-matrix composites reinforced with ceramic particulates in dry sliding against a semi-metallic frictional material. Tribology 21(4):251-255

Zhang H, Gao D, Liu D et al (2012) Experimental studies of rock abrasiveness using a fractal approach. Int J Rock Mech Min Sci $54: 37-42$

Zhao J, Deng J, Xie Y et al (2011) Establishment and application of a universal prediction model of formation abrasivity. China Offshore Oil Gas 23(5):329-334

Publisher's Note Springer Nature remains neutral with regard to jurisdictional claims in published maps and institutional affiliations. 